\title{
Quality assessment of a new in-mould slurry deposition method for triaxial specimen reconstitution of clean and silty sands
}

\author{
Camelia Dominguez-Quintans ${ }^{1, *}$, V. Santiago Quinteros ${ }^{1,2}$, J. Antonio H. Carraro ${ }^{1}$, Lidija Zdravkovic ${ }^{1}$, and Richard J. \\ Jardine $^{1}$ \\ ${ }^{1}$ Imperial College London, ICL, London, United Kingdom \\ ${ }^{2}$ Norwegian Geotechnical Institute, NGI, Oslo, Norway
}

\begin{abstract}
An innovative specimen reconstitution technique for sandy and silty soils that simulates underwater deposition is presented and evaluated. The technique is an upgraded version for triaxial testing of the well-established slurry deposition method. This novel setup integrates the reconstitution mould and the mixing tube into a single unit to avoid transferring the sample from the mixing tube to the mould. This subtle, but critical, modification enables reconstitution of very loose specimens as sample transfer disturbance, which can be significant, is eliminated. The quality of specimens prepared by the new reconstitution method was assessed by experiments on a clean sand from the UK (Ham River sand) and a silty sand from Norway (Øysand). The method, as any slurry-based procedure, is capable of producing homogeneous specimens with high initial degree of saturation, even in the absence of back pressure. The procedure is shown to be suitable for sands with or without fines. Moreover, the new method is able to achieve a wide range of initial void ratios, from very loose to very dense, without imposing any particle crushing in the latter case.
\end{abstract}

\section{Introduction}

Sampling of sands is a major challenge for geotechnical analyses that rely on the use of high-quality undisturbed samples to model soil behaviour. While sampling techniques such as ground freezing have been used for research and in practice [1-2], such techniques are often deemed unfeasible on technical or economic grounds. The mechanical behaviour of sands in the laboratory is usually examined by testing reconstituted specimens, where the most widely used laboratory reconstitution techniques are moist tamping, air pluviation and water pluviation. A critical requirement for any reconstitution method is its ability to simulate in situ soil fabric as closely as possible so that the behaviour inferred from reconstituted specimens is representative of the sand in situ.

Experimental evidence shows that water pluviation is the most suitable technique to simulate the in situ fabric of sands deposited under water [1,3-4]. Water pluviation is representative of a variety of applications including offshore sands, tailing dams and fluvial deposits. However, water pluviation is only suitable for specimen reconstitution of relatively uniform sands without fines. Specimen reconstitution of well-graded sands or sands with fines by water pluviation yields low-quality, nonuniform specimens [5]. Slurry deposition was introduced as a modification of the water pluviation method for triaxial testing of well-graded and nonplastic silty sands [5]. The method was later extended to sands with either plastic or nonplastic fines and preparation durations shortened to less than an hour [6]. In the slurry deposition method described by Carraro and Prezzi [6], the sample is pluviated through a column of water or slurry (the latter being necessary for sands with fines) inside a mixing tube with diameter slightly smaller than the reconstitution mould. The tube is agitated and rotated around its axis for several minutes to homogenise the sample and then quickly placed inside a mould half-filled with deaired water. Once the sample settles inside the mixing tube, the tube is carefully raised to allow the sample to transfer into the mould.

The new method presented and evaluated herein has the same advantages of the original slurry deposition method. It yields saturated, homogeneous, uniform specimens with fabric and mechanical behaviour similar to sands deposited underwater in the field. However, the new method has a key improvement: the reconstitution mould is included as an integral part of the mixing apparatus, which avoids transferring the sample from the mixing tube to the mould. This prevents lateral migration of soil particles and undesired sample densification of very loose sands. Details of the new procedure and quality assessment techniques applied are described below.

\section{Soils tested}

Ham River sand (HRS), which is a clean, uniform medium-fine grained sand graded from the Thames valley gravels near London (UK) and Øysand, a silty sand from Trondheim (Norway) were tested. Their particle size distributions are shown in Figure 1, while their basic index properties are listed in Table 1.

\footnotetext{
* Corresponding author: camelia.dominguez16@imperial.ac.uk
} 


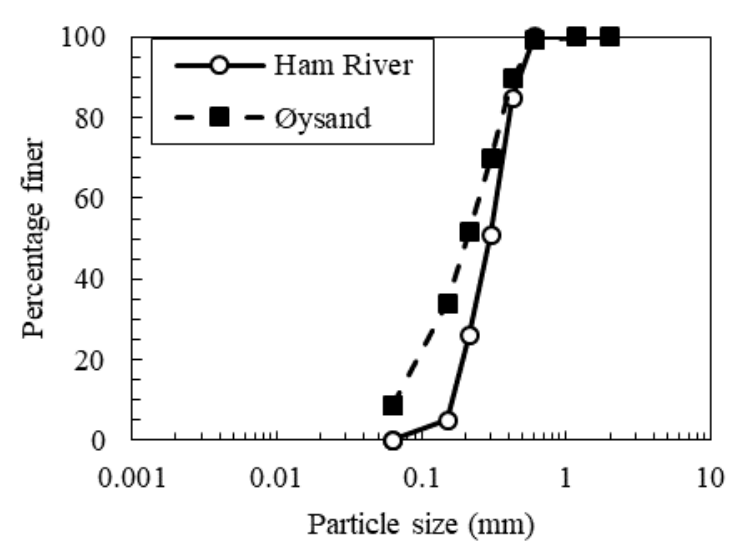

Fig. 1. Particle size distributions of the sands tested.

Table 1. Index properties of Ham River sand and Øysand.

\begin{tabular}{lll}
\hline Property & HRS & Øysand \\
\hline Specific gravity, $\mathrm{G}_{\mathrm{s}}$ & 2.66 & 2.74 \\
Uniformity coefficient, $\mathrm{C}_{\mathrm{u}}$ & 2.1 & 3.6 \\
Determination coefficient, $\mathrm{C}_{\mathrm{c}}$ & 4.2 & 7.4 \\
USCS group symbol & $\mathrm{SP}$ & $\mathrm{SP}-\mathrm{SM}$ \\
Fines content $(\leq 63 \mu \mathrm{m})(\%)$ & 0 & 9 \\
Mineralogy & Quartz & Quartz \\
Roundness & Sub-angular & Angular \\
& to sub-rounded & \\
Sphericity & High & Low \\
\hline
\end{tabular}

Table 2. Maximum void ratios of sands tested (repeatability).

\begin{tabular}{llll}
\hline Soil/Method & $\begin{array}{l}\text { No. trials } \\
(-)\end{array}$ & $\begin{array}{l}\text { Average } \\
(-)\end{array}$ & $\begin{array}{l}\text { COV } \\
(\%)\end{array}$ \\
\hline Ham River sand & & & \\
\hline Imperial College $^{1}$ & 9 & 0.826 & 1.0 \\
ASTM $^{2}$ & 10 & 0.812 & 0.7 \\
$\mathrm{BS}^{3}$ & 10 & 0.799 & 1.1 \\
\hline Oysand $^{3}$ & & & \\
\hline Imperial College $^{1}$ & 9 & 0.996 & 3.5 \\
ASTM $^{2}$ & 11 & 0.892 & 1.0 \\
BS $^{3}$ & 11 & 0.906 & 1.5 \\
\hline
\end{tabular}

${ }^{1}$ Based on the slurry method of Carraro and Prezzi [6]

${ }^{2}$ ASTM D4254-16 (Method B) [8]

${ }^{3}$ BS 1377-4:1990 (Section 4.4) [9]

While both soils are predominantly silica sands, they present very different particle shapes. Microscopy images displayed in Figure 2 illustrate that Ham River sand particles are mainly sub-angular to sub-rounded and spherical, whereas Øysand grains are more angular.

\subsection{Limiting void ratios}

Relative density is a useful index to systematically compare the density states of sands. Relative density quantifies the relative location of the density state of a sand within the possible range defined by its maximum and minimum void ratios ( $\mathrm{e}_{\max }$ and $\mathrm{e}_{\min }$, respectively). Although the concept is simple and widely used in practice, proper determination of relevant limiting void ratios is not straightforward. Experimental studies have demonstrated that $\mathrm{e}_{\max }$ is highly dependent on the method used for its determination [7].

In the present study, three different techniques were used to determine the $\mathrm{e}_{\max }$ of both sands: a new slurrybased method (modified after Carraro and Prezzi [6]),
ASTM D4253 Method B [8] and BS 1377-4:1990 Section 4.4 [9]. Table 2 shows the basic statistics of these determinations.

The $\mathrm{e}_{\max }$ results obtained using the new slurry method developed at Imperial College are based on the earlier approach proposed by Carraro and Prezzi [6]. These results are repeatable and deemed to be most representative of the maximum void ratio that can be achieved underwater (or in a slurry environment), as this method involves underwater deposition.

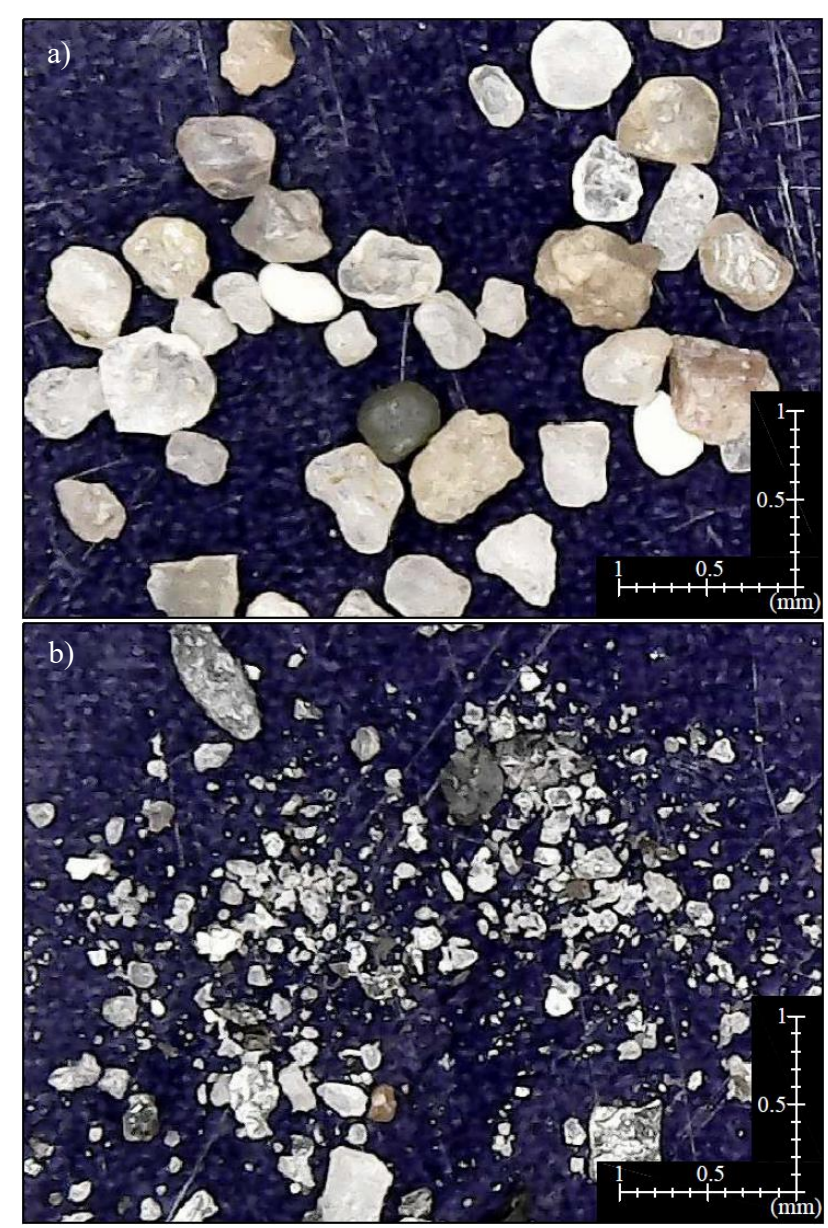

Fig. 2. Microscopy images of a) Ham River sand and b) Øysand particles.

In contrast, all ASTM and BS methods (including the high-repeatability ones selected for this study) rely on determinations carried out on dry samples, which are unsuitable to replicate the fabric of offshore sediments, tailings dams and fluvial deposits. Therefore, slurry-based values are used in all relative density assessments described later. IC $\mathrm{e}_{\max }$ values are also the largest ones measured due to the lower energy environment imparted by underwater deposition [10].

The minimum void ratio $\left(\mathrm{e}_{\mathrm{min}}\right)$ values used in this study are 0.549 for Ham River sand [11] and 0.598 for Øysand. The Ham River sand value was determined according to BSI [9]: 3 layers are vibrated inside a 1-L mould with a hammer for 2 minutes. The Øysand value was obtained according to the dry NGI in-house method [7]: $0.5 \mathrm{~kg}$ of sand is placed inside a mould in thin layers and vibrated with a hammer for 30 seconds with a 4.2 $\mathrm{kN} / \mathrm{m}^{2}$ surcharge. 


\section{Specimen preparation}

\subsection{Experimental setup}

Development of the upgraded procedure outlined here required fabrication of special parts to be used in conjunction with a conventional 38-mm-diameter split mould with height to diameter ratio of two (Figure 3a). The new additional part is the extension collar (Figure $3 b$ ), which essentially doubles the height and volume of the mould. A new collector was designed as a toroid hollow ring to retain an amount of soil/slurry equal to the inner volume of the extension collar. This helps keep the process clean. The collector is first placed on top of the mould. Then, the extension collar sits on top of the collector as shown in Figure 3b. The collar top is sealed with a rigid cap with a drainage hole in its centre. The bottom side of the cap houses an O-ring that seals the system. This cap can be simply placed on top of the collar, without the need for squeezing it into the collar. When the cap is firmly held and slightly pressed against the collar, the O-ring successfully seals the system whilst allowing easy cap removal afterwards. a)

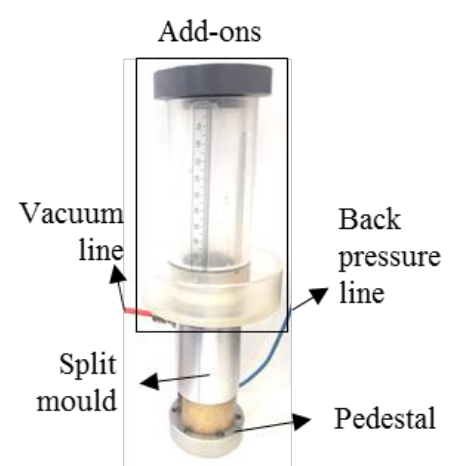

b)

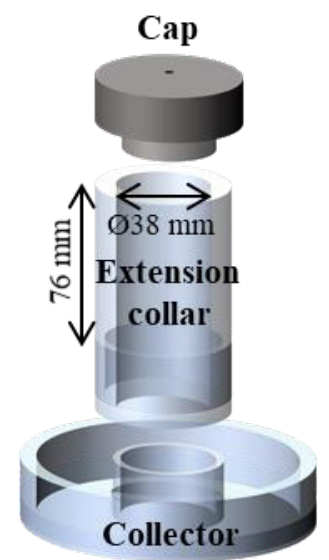

Fig. 3. Experimental device: a) complete setup and b) schematic representation of the newly designed add-ons.

\subsection{Soil sample design and densification}

Like any other slurry-based reconstitution technique, the present method requires a greater amount of soil to be used during mixing than that required to achieve the target void ratio and produce the final specimen volume inside the split mould. Therefore, to define a suitable initial dry mass of soil, uniformity assessments were carried out prior to the start of the triaxial testing programme. This initial mass of soil must ensure that sample deposition inside the split mould takes place uniformly for both loose and dense states. The top of the pluviated sample (inside the entire apparatus) usually manifests segregated conditions and must be kept far enough from the final specimen top (inside the mould) to ensure specimen uniformity and homogeneity. This is particularly critical for well-graded sands and sands with fines, for which the entire sample mass might need to increase to about 1.5 to 2 times the final mass of the specimen.
In this study, denser specimens were obtained using a vibratory table capable of inducing a vertical vibration amplitude of $0.1 \mathrm{~mm}$ at $50 \mathrm{~Hz}$. Uniformity assessment of denser states obtained with this method was conducted for the Ham River sand as presented in section 4.1. Appropriate densification curves were produced at the start of the experimental programme to provide specimen densification guidelines linking target relative densities with the corresponding vibration time required. Typical densification curves for the sands tested are shown in Figure 4 based on the $\mathrm{e}_{\min }$ and IC $\mathrm{e}_{\max }$ values listed in Table 2. These curves were obtained by stopping the vibration after a set time periods and waiting until sample settlement visually stopped inside the collar. As shown in Figure 4, the clean Ham River sand showed faster initial densification than Øysand, which contains a significant fines fraction (Figure 1).

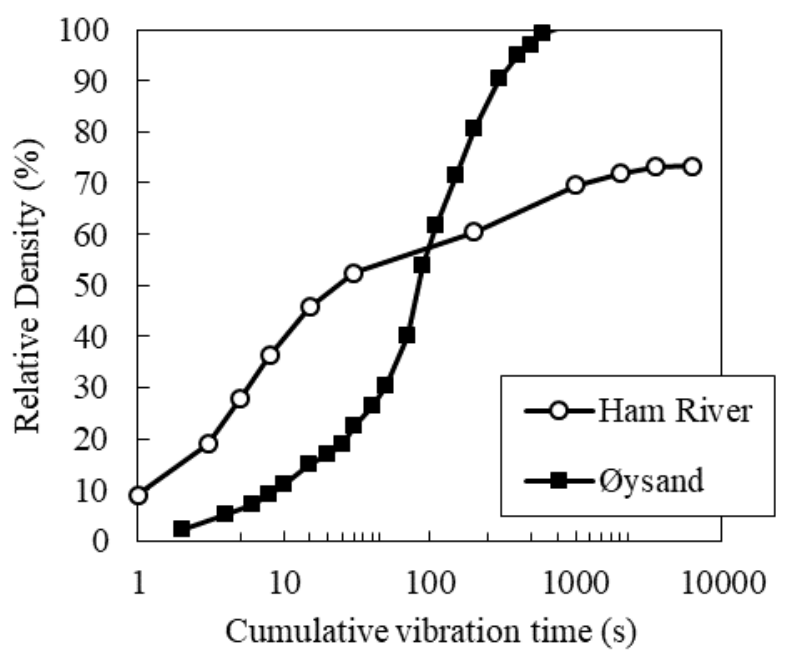

Fig. 4. Examples of densification curves for the two sands tested.

\subsection{Reconstitution procedure}

The entire reconstitution method is schematically shown in Figure 5. This procedure was originally developed to be used with rough ends and includes the following steps:

i. The base pedestal is detached from the triaxial cell base and placed on a horizontal surface. Base pedestal drainage lines are connected to the back pressure line and saturated. A filter paper is placed on the pedestal under the porous disc to avoid future filter paper movement during mixing. A rubber membrane is positioned and sealed against the base pedestal with O-rings and the split mould is set up over the membrane. Once the membrane is rolled up and over the mould top, vacuum is applied to keep the membrane flush with the internal mould surface. The collector is placed over the rolled membrane on the mould top and the extension collar is attached to the collector. This entire arrangement constitutes the full compound mixing tube (Figures 5a and 3a). Special care is used to avoid membrane damage and prevent leakages between the collector, extension collar and split mould. All new add-on parts are 
designed to fit each other with minimal clearance, but vacuum grease may be needed due to typical membrane thickness variations.

ii. The compound mixing tube is subsequently half filled with fresh deaired water (Figure $5 \mathrm{~b}$ ) and the predefined amount of soil (section 3.2) is poured through a funnel (Figure 5c) as slowly as possible to minimise air entrapment in the sample. The tube is then topped up with deaired water and the cap is installed allowing any extra water to exit through the drainage hole. Adhesive tape may be used to cover the hole, if desired (Figure 5d).

iii. As the back pressure line remains connected to the base pedestal and vacuum is applied to eliminate the membrane-mould gap, a cylindrical cavity is formed across the entire length of the compound mixing tube, which is thoroughly and continuously agitated for several minutes (Figure 5e). When the sample inside the mixing tube looks well mixed and homogeneous, the tube is turned upside down for the last time, then turned back up to its final vertical position, and placed in its final location on the triaxial cell base. This last step must be done very carefully if a very loose state is to be achieved (Figure 5f). The base pedestal is secured to the triaxial cell base and the mixture is allowed to settle inside the tube for about 10 minutes or until the water/slurry in the tube top clears.

iv. If a denser state is required, the compound mixing tube is placed on a shaking table (instead of the triaxial cell base) for a defined period (Figure $5 \mathrm{~g}$ ) following the densification curves previously obtained for a given soil (Figure 4). When the target density is achieved, the mixing tube is placed and secured onto the triaxial cell base as described in step iii.

v. Adhesive tape (if used) is then removed to open the cap drainage hole and the cap is carefully removed (Figure 5h). Excess water/slurry is extracted from the tube top with a syringe until the top of the deposited soil column is no longer submerged. Then, the extension collar is carefully removed (Figure 5i). The specimen top is levelled using a straight edge in two horizontal strikes, with each strike always starting from the centre to the edge of the mould (Figure $5 \mathrm{j}$ ). The collector including any leftover sample is then carefully removed (Figure $5 \mathrm{k}$ ). The rolled over membrane is carefully cleaned to remove any remaining soil grains.

vi. Specimen reconstitution is finished. The filter paper, porous disc and top cap can be installed on the specimen top. The membrane is rolled up and sealed against the top cap with O-rings (Figure 51). A 15$20-\mathrm{kPa}$ vacuum is applied to the specimen before the split mould is removed and the base pedestal is firmly secured to the triaxial cell base without disturbing the specimen.

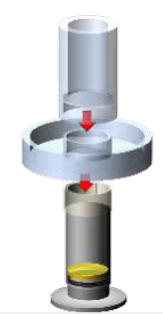

a)

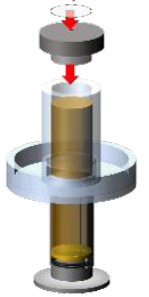

d)

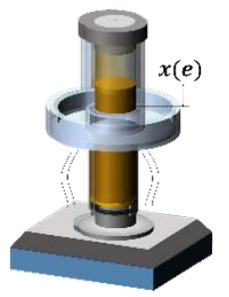

g)

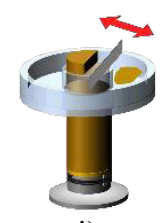

j)

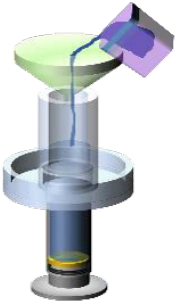

b)

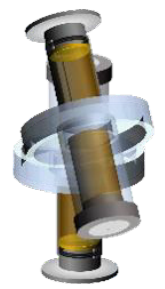

e)

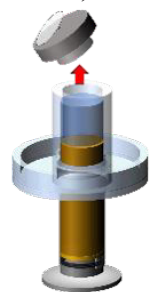

h)

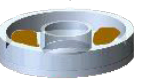

1

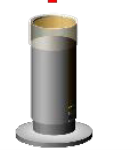

k)

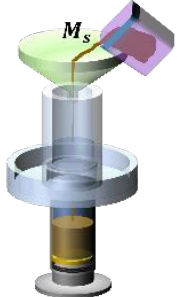

c)

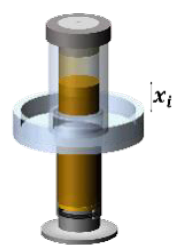

f)

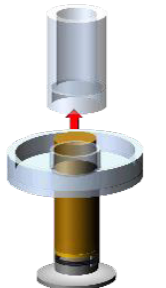

i)

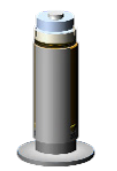

1)
Fig. 5. Schematic procedure of specimen reconstitution.

\section{Quality assessment}

\subsection{Specimen uniformity}

Specimen uniformity for both loose and medium-dense states obtained with the proposed reconstitution method was evaluated across their height using a 4-part density gradient mould (Figure 6a). Uniformity specimens were prepared by substituting water with a $2.3 \%$ gelatine solution (by weight) as outlined by Emery et al. [12]. The gelatine solution was prepared with water at around $90^{\circ} \mathrm{C}$. Once the gelatine solidified, the specimen is carefully cut with a wire saw through each interlayer joint. The contents of each of the four layers are then carefully washed with hot water to obtain the dry mass of each layer. Uniformity assessments for the Ham River sand are shown in Figure 6b, covering very loose (with states around $\mathrm{e}_{\max }$ ) and medium dense (relative density around $60 \%$ ) specimens. Maximum absolute relative densities deviations (from average values) are less than $0.9 \%$ for the looser state and $3.5 \%$ for the denser state. Considering the high sensitivity of void ratio measurements for the small (38 $\mathrm{mm}$ diameter and $19 \mathrm{~mm}$ high) slices, these results can be considered satisfactory and in line with the few previous studies where specimen uniformity was 
evaluated. Kuerbis and Vaid [5] assessed their slurrydeposited triaxial specimens yielding a maximum deviation of around $5 \%$, while Carraro and Prezzi [6] reported a deviation lower than $3 \%$. Tastan and Carraro's [13] hollow cylinder specimens prepared using the slurry deposition gave maximum deviations in the range of 3 to $7 \%$, while Ghionna and Porcino [1] reported maximum deviations from the average of around $7 \%$ using water pluviated triaxial specimens.

Figure 7 plots the particle size distribution of each one of the 4 slices for the same uniformity specimens shown in Figure 6b. Figure 6a shows the location of the slices referred to in Figure 7. Figures 6 and 7 demonstrate that uniform and homogenous specimens are produced with the proposed method in terms of density and particle size distributions across the specimen height.

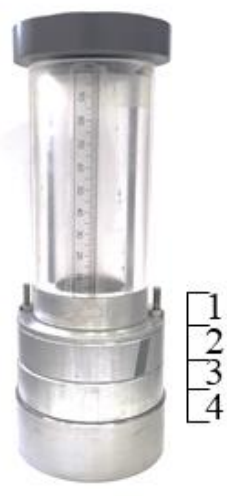

a)

b)

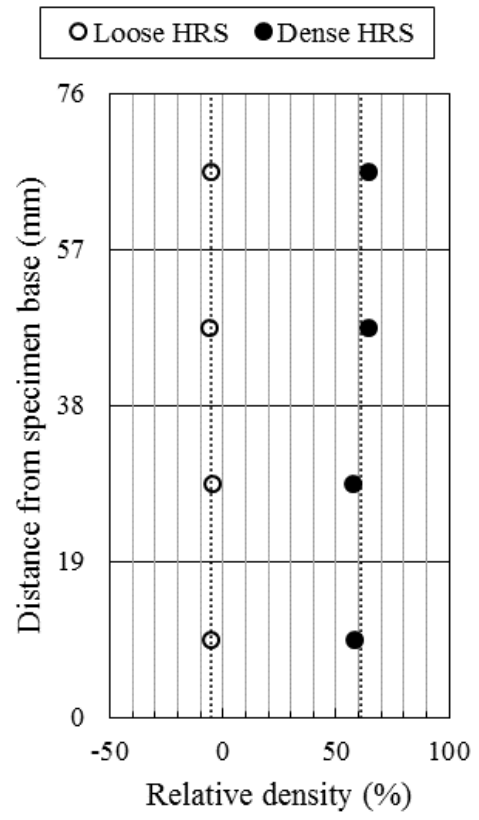

Fig. 6. a) 4-part density gradient mould and b) uniformity assessment of Ham River sand in terms of relative density.

\subsection{Specimen saturation}

One of the advantages of the slurry deposition method is the possibility of achieving high initial degrees of saturation even without back pressure [6]. This holds true for the revised method proposed in this paper (Figure 8). The B-values obtained after flushing and under no back pressure $(0 \mathrm{kPa})$ are shown along with values obtained during back pressure saturation. The proposed procedure yields initial B-values higher than 0.7 even in the absence of back pressure.
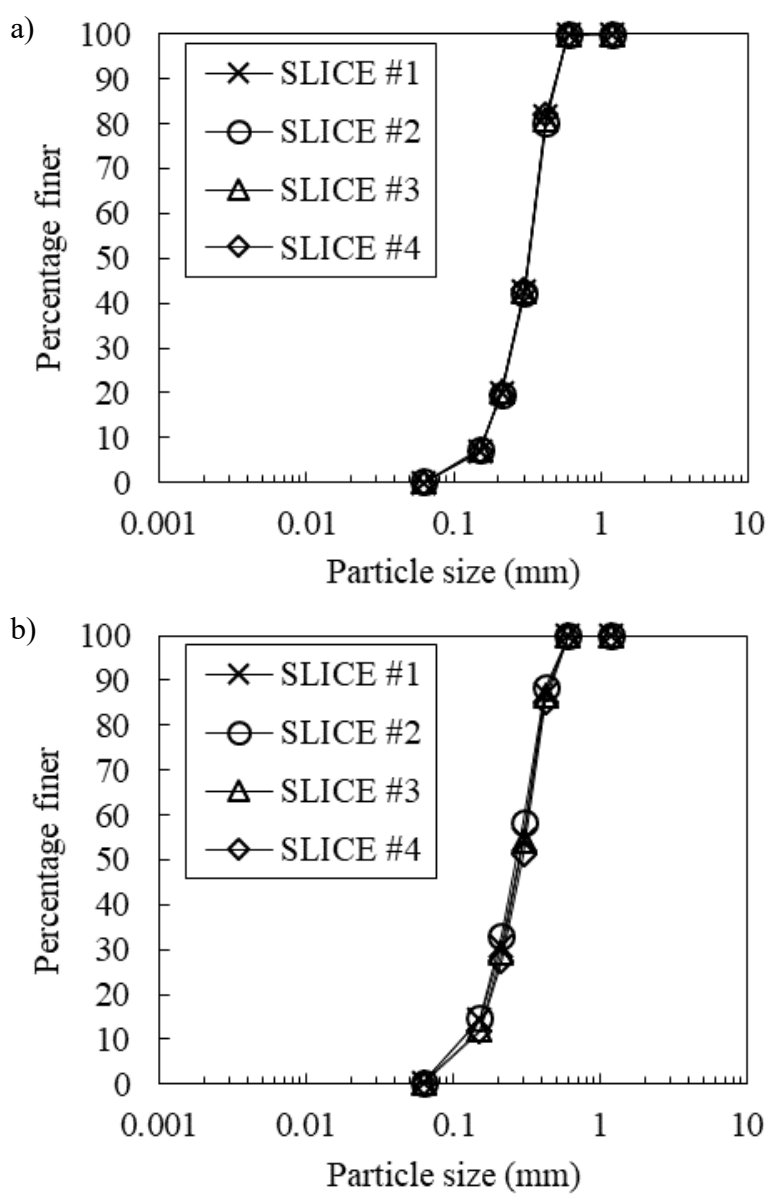

Fig. 7. Uniformity assessment in terms of particle size distribution for a) loose and b) dense Ham River sand.

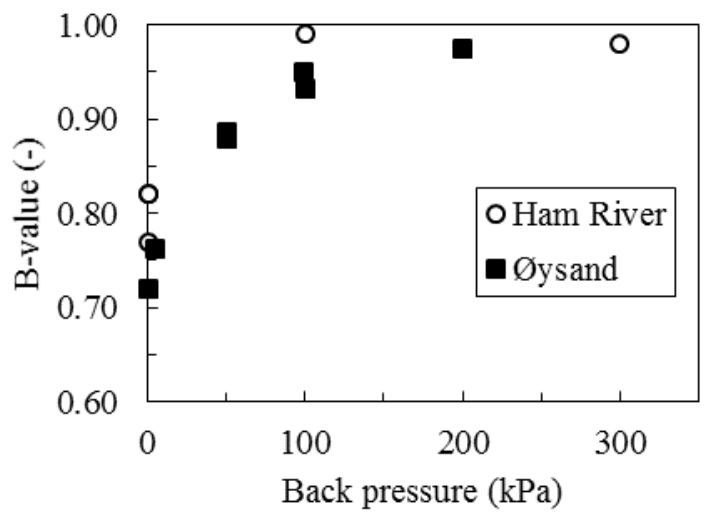

Fig. 8. Typical B-values after flushing and backpressure saturation obtained with the proposed reconstitution method.

\subsection{Particle crushing}

The densification procedure presented here, which makes use of vibration, does not induce any noticeable particle crushing for the tested sands. Particle size distribution (PSD) analyses of specimens reconstituted with the proposed method and densified by vibration show negligible discrepancies, as shown in Figure 9. This is expected given that the two samples tested are silica sands. 


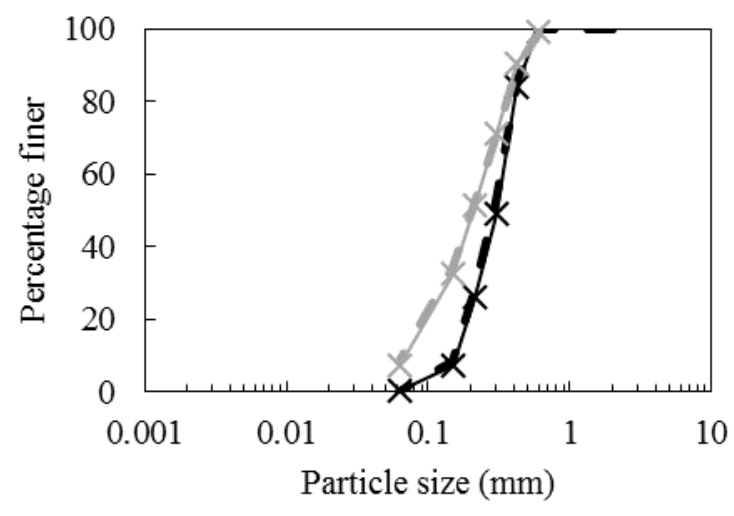

- - HRS original PSD

$\rightarrow$ HRS reconstituted $\mathrm{Dr}=75 \%$

- Øysand original PSD

$\leftarrow$ Øysand reconstituted $\mathrm{Dr}=100 \%$

Fig. 9. Assessment of particle crushing after densification.

\subsection{Typical monotonic undrained response}

Examples of effective stress paths from undrained triaxial compression tests on Ham River sand specimens reconstituted with the proposed method are plotted in Figure 10. At similar states (of density and stress), the method produces specimens that tend to show more dilative behaviour than their counterparts obtained with other reconstitution methods. As noted in the literature, water pluviation/slurry deposition techniques produce a different and more representative soil fabric than other reconstitution methods [1,3-4].

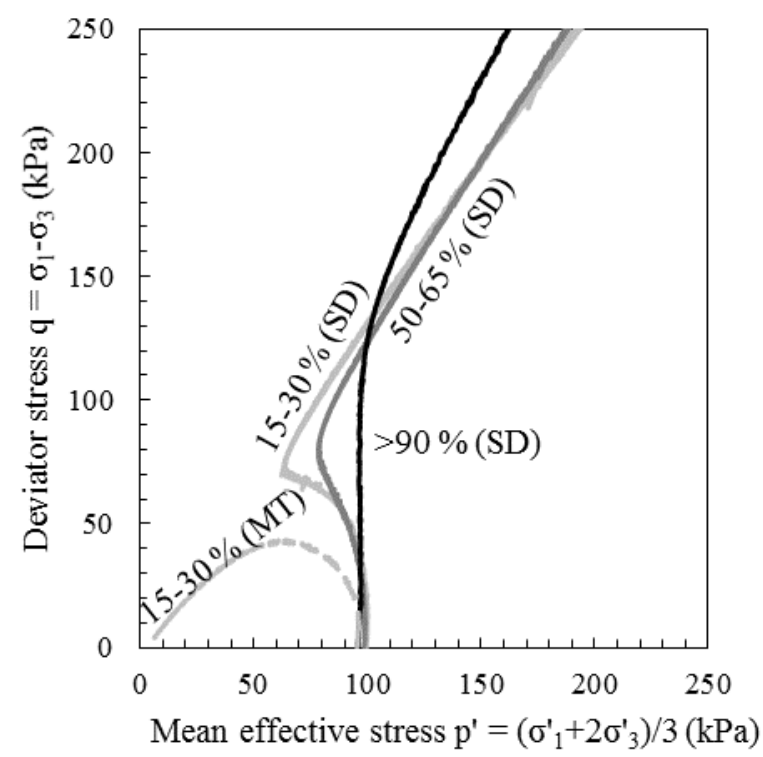

Fig. 10. Undrained effective stress paths for isotropically consolidated Ham River sand specimens reconstituted with the in-mould slurry deposition method proposed in this study (SD) and a loose specimen reconstituted with the moist tamping method (MT).

\section{Summary and Conclusions}

1) A novel in-mould slurry deposition technique is presented for reconstituted sands that simulates underwater deposition in the laboratory and avoids transference of the sample from the mixing tube to the reconstitution mould.

2) Uniformity assessments for Ham River sand demonstrate that the method produces homogenous specimens that saturate easily.

3) The method can produce specimens with a wide range of relative densities, covering very loose to very dense states.

The work presented in this paper is part of the $\mathrm{PhD}$ research of the two lead authors, funded, respectively, by the Department of Civil and Environmental Engineering at Imperial College through Skempton Scholarship, and by the Norwegian Geotechnical Institute and the Norwegian Research Council. The authors thank Mr. Graham Keefe and Mr. Stef Karapanagiotidis at Imperial College for their technical support in producing main equipment.

\section{References}

1. N. Ghionna and D. Porcino. J. Geotech. Geoenviron. Eng., 132, 2, 194-202 (2006)

2. C.E. (Fear) Wride, B.A. Hofmann, D.C. Sego, H.D. Plewes, J.M. Konrad, K.W. Biggar, P.K. Robertson, and P.A. Monahan. Can. Geotech. J., 37, 530-542 (2000)

3. K. Høeg, R. Dyvik, and G. Sandbækken. J. Geotech. Geoenviron. Eng., 126, 7, 606-617 (2000)

4. Y.P. Vaid, S. Sivathayalan, and D. Stedman. Geotech. Test. J., 22, 3, 187-195 (1999)

5. R. Kuerbis, and Y.P. Vaid. Soils Found., 28, 4, 107118 (1988)

6. J.A.H. Carraro and M. Prezzi. Geotech. Test. J., 31, 1, 1-11 (2007)

7. Ø. Blaker, T. Lunne, T. Vestgården, L. Krogh, N. V. Thomsen, J.J.M. Powell and C.F. Wallace. ISFOG 1159-1166 (2015)

8. ASTM D4254 - 16 (2016)

9. BS 1377-4: 1990 (2010)

10. Y.P. Vaid and D. Negussey. Soils and Found., 24, 3, 101-105 (1084)

11. A. Takahashi and R.J. Jardine. Q. J. Eng. Geol. Hydroge., 10, 93-103 (2005)

12. J.J. Emery, W.D. Liam, and K.W. Lee. ASTM STP 523, 182-194 (1973)

13. E.O. Tastan and J.A.H. Carraro. Geotech. Test. J., 36, $6,811-822(2013)$ 